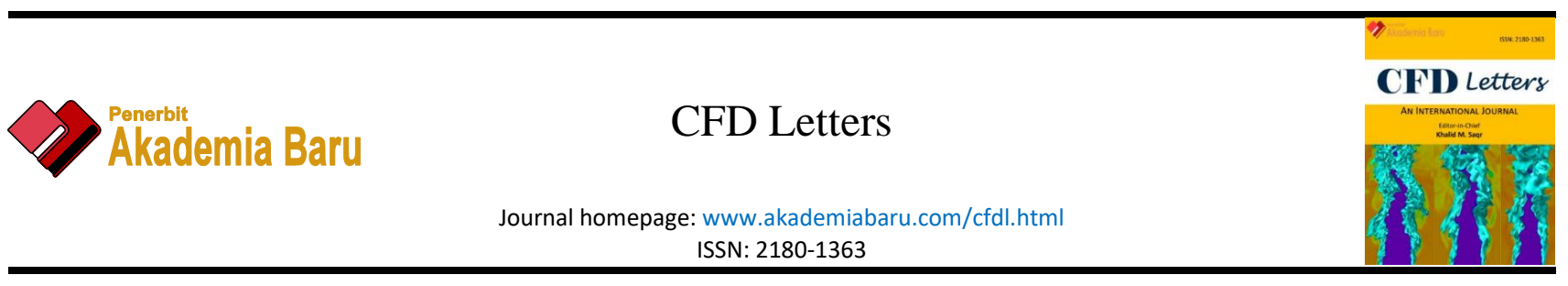

\title{
Drag Penalty Causing from the Roughness of Recently Cleaned and Painted Ship Hull Using RANS CFD
}

\author{
Muhammad Luqman Hakim ${ }^{1}$, Bagus Nugroho ${ }^{2}$, Rey Cheng Chin $^{3}$, Teguh Putranto ${ }^{1}$, I Ketut \\ Suastika ${ }^{1}$, I Ketut Aria Pria Utama ${ }^{1 *}$
}

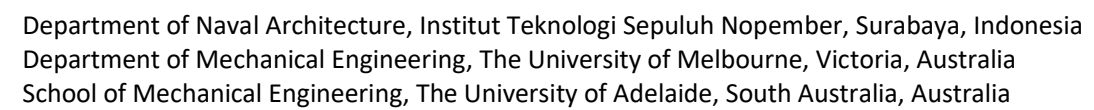

\section{ARTICLE INFO}

Article history:

Received 23 January 2020

Received in revised form 18 March 2020

Accepted 23 March 2020

Available online 29 March 2020

Keywords:

Surface roughness; ship resistance; frictional resistance; biofouling; RANS.

\section{ABSTRACT}

The issue of global warming makes energy savings on ships compulsory. One of the biggest causes of energy waste is the increase in friction resistance due to the hull roughness that makes not hydraulically smooth. The process of cleaning and repainting the ship hull turned out to make a roughness that can provide a drag penalty. An investigation using a resolved Reynolds-averaged Navier-Stokes (RANS) Computational Fluid Dynamics (CFD) approached to assess the increase in ship resistance from a recently cleaned and painted ship hull roughness are reported. The rough surface was obtained through surface imprint during its annual dry-docking and digitized via a laser scanner. A roughness geometry that was obtained from the scanning was prepared for the CFD simulations. The results for two ships show that such surface would cause an increase in friction resistance of the full-scale ship by $33 \%-35 \%$, which corresponds to an increase in the ship's total resistance by $7.5 \%-28 \%$. The type of ship that is mostly affected by the roughness is a ship with a higher frictional resistance ratio (lower Froude Number) compared to residual resistances, where most of them are large ships.

Copyright @ 2020 PENERBIT AKADEMIA BARU - All rights reserved

\section{Introduction}

The issue of global warming and climate change forced the International Maritime Organization (IMO) to regulate emission levels on ships. Based on the $\mathrm{IMO}$ record, $\mathrm{CO}_{2}$ emissions due to all maritime activities around the world compared to all emissions were around 2.2\% in 2012 [1]. Then if the emissions from ships around the world compared to other modes of transportation were $11 \%$ [2]. IMO predicted that the emission would increase by $50 \%$ to $250 \%$ in 2050 if it is not anticipated immediately [3]. Even though $95 \%$ of the entire world cargo is carried by ships [4]. Thus, IMO amended MARPOL Annex VI regulation by adding the Energy Efficiency Design Index (EEDI) [5] and

\footnotetext{
* Corresponding author.

E-mail address: kutama@na.its.ac.id (I Ketut Aria Pria Utama)
} 
the Ship Energy Efficiency Management Plan (SEEMP) program [6]. These forces the parties involved to care about the use of energy on ships.

One of the energy wastage on ships is the increased power requirements due to roughness on the hull surface (not hydraulically smooth) [2,7]. Surface roughness can cause increased friction resistance, which then causes increased power requirements, and finally, fuel consumption and emission increases. Because of roughness, fuel consumption on a ship increased by up to $20 \%$ in a year [8], and overall losses reached up to $\$ 56$ million in a year [9].

The hull surface roughness generally occurs due to biofouling. Biofouling is the accumulation of aquatic organisms that can stick to the surface or structure of submerged objects, like a ship hull [10]. Biofouling consists of various types, and each type has different shape geometry, for example, barnacle and slime. Because they have different geometric shapes, then they will produce different increased drag. Many of Laboratory testing and numerical simulations related to predictions of increased resistance due to biofouling have been carried out. Schultz [11] conducted a towing tank experiment for some types of roughness, namely light slime, heavy slime, calcareous fouling, medium calcareous fouling, and heavy calcareous fouling. Demirel et al., [12] continued by predicting an increase in ship resistance due to biofouling from Schultz [11] on the Kriso Container Ship (KCS) model using CFD, where the result of an increase in ship resistance reached $130.9 \%$. The predicted increase in drag due to barnacle was also carried out by Demirel et al., [13], Uzun et al., [14], and Sarakinos and Buse [15]. Monty et al., [16] conducted the wind-tunnel experiment using light calcareous tubeworm fouling, which could increase the resistance of a Very Large Crude Carrier (VLCC) vessel up to $34 \%$.

Besides from biofouling, surface roughness on ships can also arise from anti-fouling paint. Although the paint roughness is only micron-sized, and it may increase the friction resistance just a little, but this can become a problem for ships with large sizes. A large bulk carrier has a composition of friction resistance about 4 to 9 times higher than the residuary resistance [17]. In the term of comparison, it looks small, but in terms of quantity, it is massive. Several studies on the effects of increased drag due to roughness in anti-fouling paint using experiments and or CFD simulation methods have been conducted by Schultz [18], Demirel et al., [19], Atencio and Chernoray [20], and certainly more. According to Demirel et al., [12], the roughness of anti-fouling paint could increase ship resistance by up to $7.1 \%$.

The ship hull that is polluted by biofouling and then cleaned, also cause surface roughness. The biofouling cleaning process on the ship hull generally uses the sandblasting method. This method can easily clean biofouling from the hull surface, and make the hull clean again. However, this also creates a roughness with micron-sized and has an impact on increasing the friction resistance. Utama et al., [21] took a sample of this roughness and called it roughness of a freshly cleaned and painted ship hull, aka "orange peel" roughness. The roughness sample was tested in wind-tunnel, and the results showed that the roughness could cause an increase in friction resistance by $31 \%$ compared to that of the ship when it was newly built (hydraulically smooth).

CFD is a low-cost engineering tool compared to laboratory testing, especially in the field of ship hydrodynamics. Conducting the CFD correctly can be proven to represent the results of laboratory tests $[12,20,22-24]$. In the case of roughness simulation mostly use Direct Numerical Simulations (DNS) [15,25-27] or Large Eddy Simulations (LES) [28-30] for its turbulence model. Where DNS and LES require more computational resources and time consuming compared to Reynolds-averaged Navier-Stokes (RANS). The RANS is often used by naval architects to review the hydrodynamics performance of a ship hull. Atencio and Chernoray [20] compared the results of a resolved RANS CFD with a set of experiments on the roughness of anti-fouling paint with a different result of about $7 \%$. 
Some others also used RANS for roughness simulations to assess the increase in friction resistance $[12,31,32]$.

In this paper, the study of the drag penalty arising from the freshly cleaned and painted ship hull roughness is explained. The method used a resolved RANS CFD, where it still used a turbulence model of RANS (SST k- $\omega$ ), but the roughness model was made with a real geometry grid, not used wall function. The roughness geometry was scanned, and it was built for the CFD geometry set up. The computational domains were created for smooth wall and rough wall condition then the boundary conditions were applied. The results of the increase in friction resistance and the total resistance were examined for full-scaled ships. Finally, an analysis of several ships of different types was also carried out using the Froude number parameter.

\section{Methodology}

\subsection{Roughness Geometry}

In this study, the surface roughness used was similar to that of Utama et al., [21]. Here an imprint made of silicone rubber was taken on the ship hull of a recently cleaned and painted, as in Figure 1a, which looks like an orange peel surface, and then it is called the "orange peel" roughness so on. The imprint was scanned using a laser triangulation sensor Keyence TM LK-031 which was attached to a two-axis computer-controlled positioning system. The laser had a vertical ( $z$ ) and horizontal ( $x$ and $y$ ) resolution of $1 \mu \mathrm{m}$ and $60 \mu \mathrm{m}$, respectively. The roughness geometry was created, and it could read in a computer file, which will later be used as the CFD numerical model set up (see Figure 1b). Figure 2 shows the resulting scan, which reveals the "orange peel" pattern. Important parameters of the roughness are tabulated in Table 1, where $z^{\prime}$ is the surface deviation about the mean height $z^{\prime}=z-$ $\bar{z}$.

Table 1

The roughness parameters of the "orange peel" roughness [21]

\begin{tabular}{|c|c|c|c|}
\hline Parameter & Value & Units & Equation \\
\hline$k_{a}$ & 0.0413 & $\mathrm{~mm}$ & ||$\overline{\mathrm{z}^{\prime}}||$ \\
\hline$k_{r m s}$ & 0.0519 & $\mathrm{~mm}$ & $\sqrt{\overline{\mathrm{z}^{\prime 2}}}$ \\
\hline$k_{p}$ & 0.4791 & $\mathrm{~mm}$ & $\max z^{\prime}-\min z^{\prime}$ \\
\hline$k_{s k}$ & 0.0868 & - & $\overline{\mathrm{z}^{\prime 3} / \mathrm{k}_{\mathrm{rms}}^{3}}$ \\
\hline$k_{k u}$ & 3.0712 & - & $\overline{\mathrm{z}^{\prime 4} / \mathrm{k}_{\mathrm{rms}}^{4}}$ \\
\hline$E S_{x}$ & 0.0890 & - & $\overline{\left|d z^{\prime} / d x\right|}$ \\
\hline
\end{tabular}

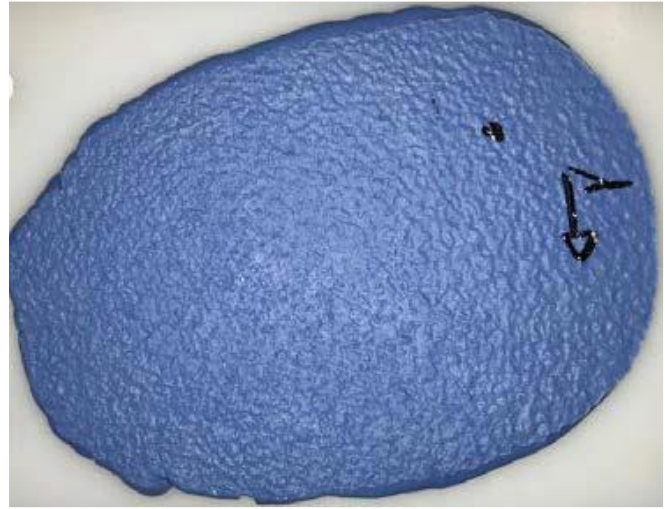

(a)

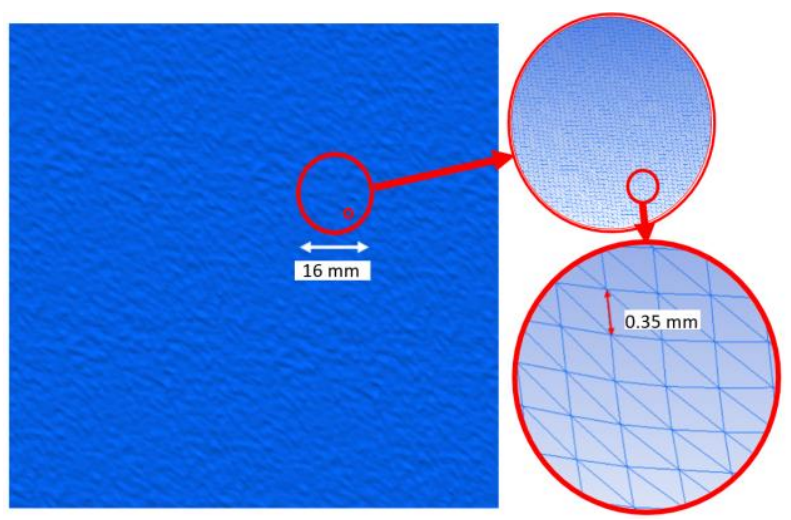

(b)

Fig. 1. (a) The imprint of the "orange peel" roughness [21], (b) The resulted geometry from the 3D scanning which was arranged of very tight grids with a maximum size of $0.35 \mathrm{~mm}$ 


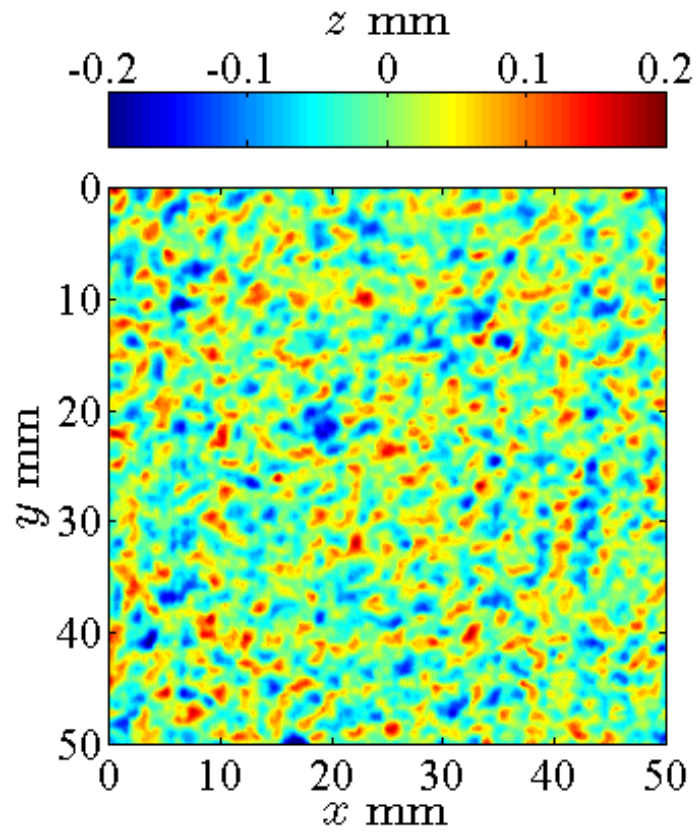

Fig. 2. The contour of the roughness height of the orange peel roughness that obtained from the 3D scanner [21]

\subsection{Numerical Formulations}

A resolved Reynold-Averaged Navier-Stokes (RANS) method was used to solve the governing equations in this study. A resolved RANS CFD has used by Atencio and Chernoray [20] with having differences with the experiment by around $7 \%$. The method is similar to commonly RANS simulation, where utilizing the turbulence model is the same, but in the case of roughness modeling, it is different. The roughness was modeled real, not used wall function, and not using $k_{s}$ (sand-grain equivalent roughness height) to downshift the velocity profile of the boundary layer. Thus, the real roughness was made from the arranged of the grids.

In this study, a steady Reynolds-Averaged Navier-Stokes (RANS) method was used to solve the governing equations. These mass and momentum conservation equations were solved by the commercial CFD software ANSYS FLUENT. For incompressible flows, the averaged continuity and the momentum equations are given in Eq. (1) and (2). Here: $\bar{U}_{l}$ is the averaged velocity component; $P$ is the mean pressure; $\rho$ is the fluid density; $\mu$ is the dynamic viscosity; $u_{i}^{\prime}$ is the fluctuation velocity component; $\rho \overline{U_{l}^{\prime} U_{j}^{\prime}}$ is the Reynolds stress, $\overline{\tau_{\imath \jmath}}$ are the mean viscous stress tensor components, as given in Eq. (3) [33]. The solver uses a finite volume method using SIMPLE algorithm, which discretizes the governing equations where the gradient used least-squares cell-based. The continuity and the momentum equations were discretized with a second-order equation, with the residual of numerical calculations were targeted less than $10^{-5}$.

$$
\begin{aligned}
& \frac{\partial\left(\rho \overline{U_{l}}\right)}{\partial x_{i}}=0 \\
& \frac{\partial\left(\rho \overline{U_{l}}\right)}{\partial t}+\frac{\partial}{\partial x_{i}}\left(\rho \bar{U}_{l} \bar{U}_{J}+\rho \overline{U_{l}^{\prime} U_{J}^{\prime}}\right)=-\frac{\partial \bar{P}}{\partial x_{i}}+\frac{\partial \overline{\tau_{l j}}}{\partial x_{j}} \\
& \tau_{i j}=\mu\left(\frac{\partial \overline{U_{l}}}{\partial x_{j}}+\frac{\partial \overline{U_{J}}}{\partial x_{i}}\right)
\end{aligned}
$$


A resolved RANS CFD still also use a turbulence model. Thus, in this simulation, The Shear Stress Transport (SST) $k$ - $\omega$ turbulence model was used in order to complete the RANS equations. It blends the $k-\omega$ model near the wall and the $k-\varepsilon$ model in the far-field. The turbulence model consists of $k$ as turbulence kinetic energy and $\omega$ as a specific dissipation rate, where these were developed by Menter [34]. The kinetic energy equation is given in Eq. (4), and the dissipation rate equation is given in Eq. (5). Detailed descriptions with these equations can be read on Menter [34]. The kinetic energy and the momentum equations were discretized with second-order upwind, and also with the residual of numerical calculations were less than $10^{-5}$.

$$
\begin{aligned}
& \frac{D \rho k}{\mathrm{Dt}}=\tau_{i j} \frac{\partial U_{i}}{\partial \mathrm{x}_{j}}-\beta^{*} \rho \omega k+\frac{\partial}{\partial x_{j}}\left[\left(\mu+\sigma_{k} \mu_{t}\right) \frac{\partial k}{\partial \mathrm{x}_{j}}\right] \\
& \frac{D \rho \omega}{\mathrm{Dt}}=\frac{\gamma}{v_{t}} \tau_{i j} \frac{\partial U_{i}}{\partial \mathrm{x}_{j}}-\beta \rho \omega^{2}+\frac{\partial}{\partial x_{j}}\left[\left(\mu+\sigma_{\omega} \mu_{t}\right) \frac{\partial \omega}{\partial \mathrm{x}_{j}}\right]+2 \rho\left(1-F_{1}\right) \sigma_{\omega 2} \frac{1}{\omega} \frac{\partial k}{\partial x_{j}} \frac{\partial \omega}{\partial x_{j}}
\end{aligned}
$$

\subsection{Geometry and Boundary Conditions of Numerical Simulation}

There were two computational models which prepared. The first was the smooth wall, which acted as the reference, and the second was the "orange peel" roughness. The roughness from Figure $1 \mathrm{~b}$ was applied to a surface plate model (like relief 2D) with sized Length $\times$ Breadth $=300 \mathrm{~mm} \times 50$ $\mathrm{mm}$. The size was relatively small, but it was chosen with consideration of the computational resources available, even this size was still greater than what was done by Atencio and Chernoray [20].

The computational domain is shown in Figure 3. Both the smooth wall and the "orange peel" rough wall had the same grid resolutions. The distance from the surface to the top boundary was 300 $\mathrm{mm}$. The symmetry boundary condition was imposed on the top and side surfaces. The symmetry ensures that the boundary condition did not affect the calculation (i.e., it could be regarded as a free slip wall). The inlet free stream $\left(U_{e}\right)$ was initialized with Reynolds number from $10^{5}-10^{11}$ using Reynold number formula in Eq. (6). Where $\rho$ is the density of the fluid, $L$ is a characteristic linear dimension, $\mu$ is the dynamic viscosity of the fluid, and $v$ is the kinematic viscosity of the fluid.

$U_{e}=\frac{R e \mu}{\rho L}=\frac{R e v}{L}$

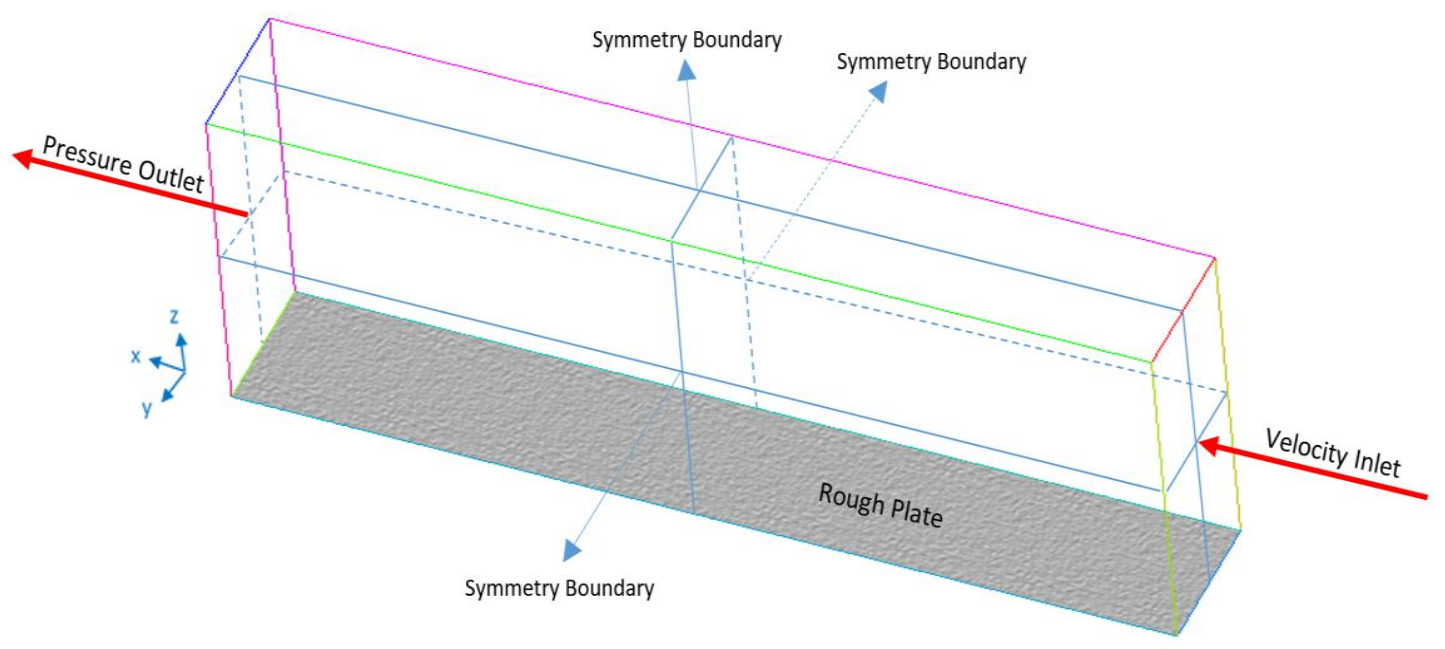

Fig. 3. Domain computation and boundary conditions description 


\subsection{Mesh Generation}

The modeling of roughness here used a real roughness made from the grids, which shown in Figure 4. Where, Figure $4 a$ was the smooth condition, and Figure $4 b$ was the rough condition with the "orange peel" roughness. Based on Figure 1 and Figure 2, the geometry could direct the grid to make similar roughness formations, as long as the size was no more than the maximum roughness size, as described in Figure $1 \mathrm{~b}$.

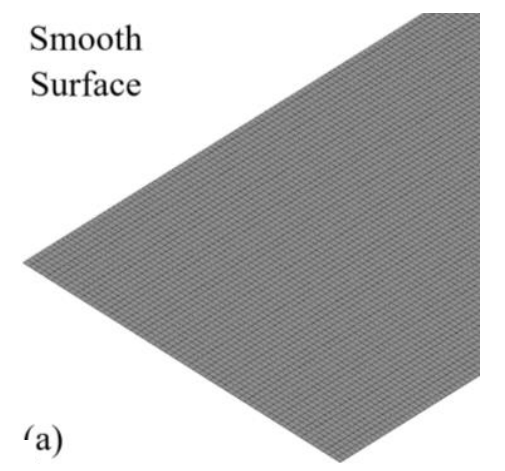

(a)

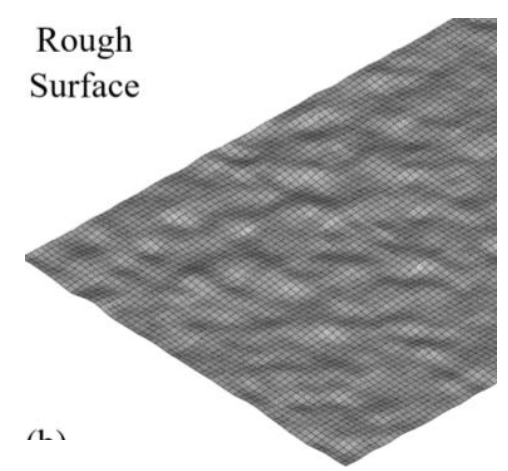

(b)

Fig. 4. The grid arrangements for smooth condition (a), and rough conditions with the "orange peel" roughness (b)

The mesh generation used structured mesh or also called the hexahedral element, with an inflation layer grid near the wall (See Figure $5 a$, Figure $5 b$, and Figure $5 c$ ). The inflation is needed to get the best value of $y^{+}$, where it was set $y^{+} \sim 1$ to keep off the buffer zone and validly simulation. The grid can be seen in Figure $5 b$ and Figure $5 c$, that the inflation of the grid is shown very tight.

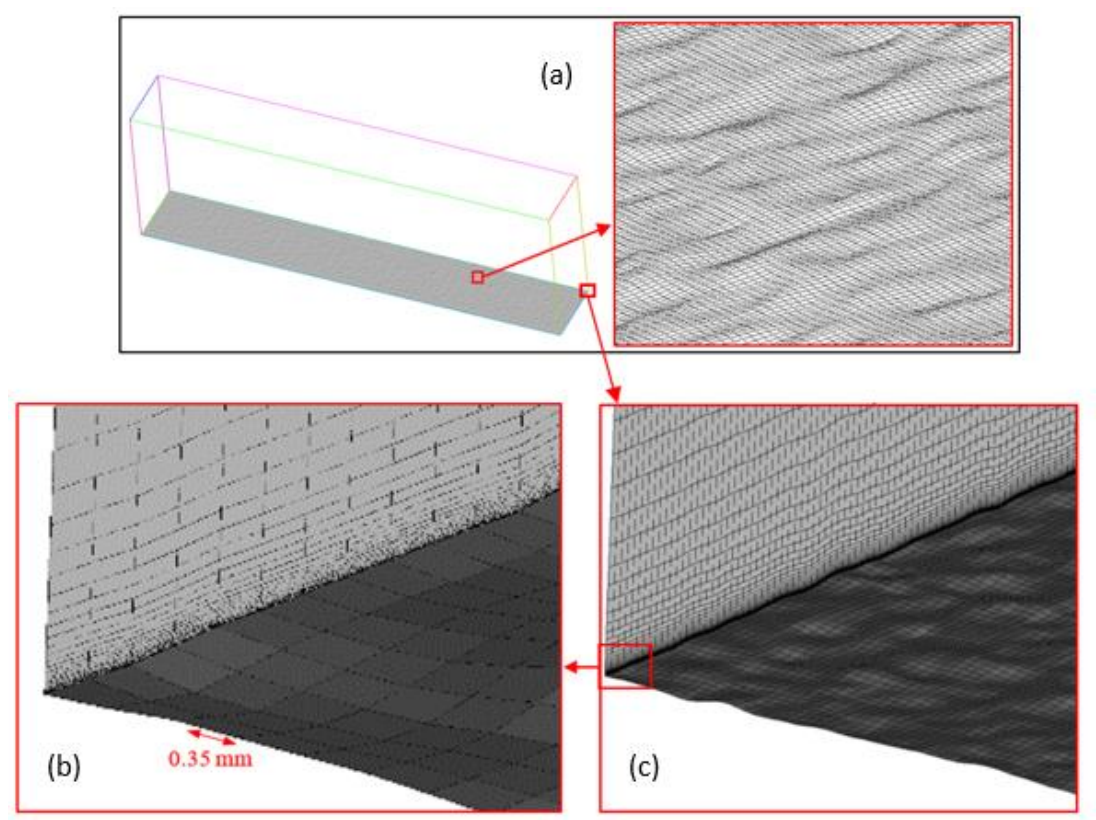

Fig. 5. (a) Mesh generation on the computational domain, (b) and (c) are the zoomed view of the rough surface grid inflation layer

The number and arrangement of elements must be tested with grid-sensitivity testing for accurate simulations. Then, the result of grid sensitivity showed that the selection with the number of elements around 6,4 million had a $0.76 \%$ difference, with 12.8 million elements, where it could 
use because it should be less than $2 \%$ [35]. The selected number of elements used the formation of the grid in Length ( 850 grids), Breadth (150 grids), and Height (50 grids).

\section{Results}

\subsection{Increase in Friction Resistance}

After performing the numerical simulations of the two models (smooth and rough), the friction resistance values were obtained. The friction resistance results were changed in non-dimensional form, friction resistance coefficient $\left(C_{F}\right)$. The formula of CF is given in Eq. (7). Where, $R_{F}$ is Friction resistance total, $\rho$ is the density of the used fluid, $S$ is the plate area, and $U$ is freestream velocity. The results from the Reynold number range of $10^{5}-10^{11}$ plotted in Figure 6 . Both two models' results were also calculated the difference percentage using Eq. (8) [16]. Where $C_{F_{S}}$ is for the smooth plate model and $C_{F_{O P}}$ is for the "orange peel" roughness plate model. They were also compared with the $C_{F}$ for smooth wall from Schoenherr [36] formula, given in Eq. (9).

$$
\begin{aligned}
& C_{F}=\frac{R_{F}}{\frac{1}{2} \rho S U^{2}} \\
& \% \Delta C_{F}=100 \times\left.\frac{\left(C_{F_{O P}-C_{F_{S}}}\right)}{C_{F_{S}}}\right|_{R e} \\
& \frac{1}{\sqrt{C_{F}}}=4.13 \times \log \left(\operatorname{Re} \times C_{F}\right)
\end{aligned}
$$

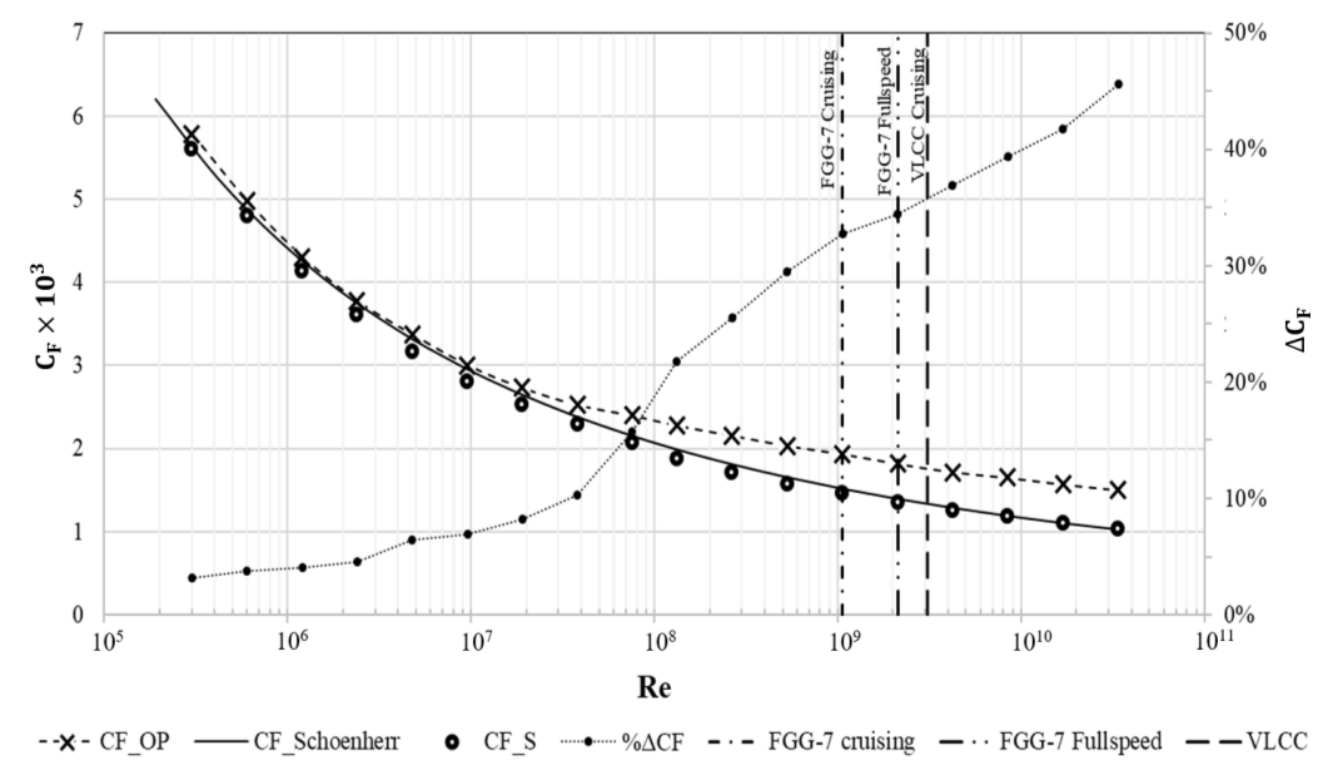

Fig. 6. The resulted plot of $C_{F}$ and $\% \Delta C_{F}$ against Reynolds numbers

From Figure 6, it can be seen that $C_{F}$ of the "orange peel" roughness was higher than $C_{F}$ of the smooth plate, and the difference percentage increased as long as increasing Reynolds numbers. At the Reynolds numbers around $10^{8}$ there was a drastic increase compared to other Reynolds number range. It $\left(\% \Delta C_{F}\right)$ increased from around $10 \%$ to around $30 \%$. According to Molland et al., [37], this was an area of critical Reynold number for $C_{F}$ value that affected from a roughness.

The increase in $C_{F}$ in full-scale ships, due to the "orange peel" roughness, were estimated for some ship types. This method was the same as what was used by Monty et al., [16]. For the example 
calculation, FFG-7 Oliver Perry-class frigate and Very Large Crude Carrier (VLCC) were used. The frigate's length was $124 \mathrm{~m}$, and the VLCC's length was $320 \mathrm{~m}$. For the Frigate, the $C_{F}$ was predicted when the ship was at cruising speed ( 15 knots) and full-speed (30 knots), while the VLCC was at cruise speed only (17 knots). From this data, the Reynolds number for each ship could be calculated. According to Figure 6 , the change in friction resistance $\left(\% \Delta C_{F}\right)$ for the Frigate at cruise speed was $32.78 \%$, while at full speed was $34.45 \%$. Then, for VLCC, the change in friction resistance $\left(\% \Delta C_{F}\right)$ was $35.52 \%$.

\subsection{Increase in Total Resistance}

Following Schultz [11] and Monty et al., [16], the increase in total resistance due to the "orange peel" roughness could be obtained using Eq. (10). Where $C_{R} / C_{F}$ is the comparison of the residual resistance values $\left(C_{R}\right)$ or wave resistance $\left(C_{W}\right)$ to the frictional resistance $\left(C_{F}\right)$. The purpose of comparing the two vessels in this case was because they have different characteristics of $C_{R} / C_{F}$ or in the form of Froude number (Fr), where the Frigate was designed for high speed vessel (higher Fr) and in contrast to the VLCC (lower Fr) then it could be seen in Table 2. Then $C_{A}$ is a correction factor released by ITTC [38], where the VLCC had smaller $C_{A}$ than that of the Frigate.

$\% \Delta C_{T}=100 \times \frac{\Delta C_{F}}{C_{F_{S}}\left(1+\frac{C_{R}}{C_{F}}\right)+C_{A}}$

Table 2

The prediction of the drag penalty due to the "orange peel" roughness

\begin{tabular}{lllllllll}
\hline $\mathrm{L}(\mathrm{m})$ & $\mathrm{C}_{\mathrm{A}}$ & $\mathrm{V}$ (knot) & $\mathrm{Fr}$ & $\mathrm{Re}$ & $\mathrm{C}_{\mathrm{R}} / \mathrm{C}_{\mathrm{F}}$ & $\% \Delta \mathrm{C}_{\mathrm{F}}$ & $\% \Delta \mathrm{C}_{\mathrm{T}}$ \\
\hline 124 & 0.0004 & Cruising & 15 & 0.22 & $1.06 \times 10^{9}$ & $\sim 0.7$ & $32.78 \%$ & $16.6 \%$ \\
& & Full-speed & 30 & 0.44 & $2.13 \times 10^{9}$ & $\sim 3.3$ & $34.45 \%$ & $7.5 \%$ \\
320 & 0.00024 & Cruising & 17 & 0.15 & $3.10 \times 10^{9}$ & $\sim 0.08$ & $35.52 \%$ & $28.1 \%$ \\
\hline
\end{tabular}

The increase in $C_{T}$ due to the "orange peel" roughness on the Frigate was predicted to be $16.6 \%$ for being on the cruising speed and $7.5 \%$ for full-speed. For the VLCC, the increase in $C_{T}$ was $28.1 \%$. The VLCC had more dominant frictional resistance because it had a higher Froude number than that of the Frigate. This case was similar to the bulk carrier that studied by Kodama et al., [17], where the bulk carrier had a ratio $C_{F} / C_{T}$ around $80-90 \%$. The results demonstrate that even a recently cleaned and painted ship hull, there was still severe drag penalty from hull imperfection.

This prediction method, which carried out by Schultz [11] and Monty et al., [16], can be used if there is no change in the wave resistance $\left(C_{W}\right)$ due to a roughness. Because according to study from Demirel et al., [12], a roughness also turned out to make the wave resistance changes, i.e. the rougher surface of the ship hull, the less the wave resistance, even though the portion was tiny.

\subsection{The Relationship of Froude Number and The Drag Penalty Due to Roughness}

The relationship between Froude number $(\mathrm{Fr})$ and the increase in $C_{T}$ due to the "orange peel" roughness was also discussed. Some additional ship resistance data with the variations in the component resistance ratio were taken from Molland et al., [7]. Each the ship was calculated Re, $\% \Delta C_{F}$, and $\% \Delta C_{T}$ as similar prediction method with the Frigate and the VLCC, and they all tabulated in Table 3. Then the all results were plotted in Figure 7, where if the $\mathrm{Fr}$ increases, the $\% \Delta C_{T}$ will decrease. Thus, it can be concluded that the effect of surface roughness can significantly increase the total resistance of ships in a low Froude number. 


\section{Table 3}

The predictions of the total drag penalty due to the "orange peel" roughness for several other ship types adopted from Molland et al., [7]

\begin{tabular}{|c|c|c|c|c|c|c|c|c|c|}
\hline \multirow[t]{2}{*}{ Type } & \multirow[t]{2}{*}{$L(m)$} & \multirow[t]{2}{*}{$C_{B}$} & \multirow[t]{2}{*}{ Speed (Kn) } & \multirow[t]{2}{*}{$\mathrm{Fr}$} & \multicolumn{3}{|c|}{ Hull resistance component (\%) } & \multirow[t]{2}{*}{$\% \Delta \mathrm{C}_{\mathrm{F}}$} & \multirow[t]{2}{*}{$\% \Delta \mathrm{C}_{\mathrm{T}}$} \\
\hline & & & & & Frict. & Form & Wave & & \\
\hline Tanker & 330 & 0.84 & 15 & 0.136 & 66 & 26 & 8 & 30.26 & 23.60 \\
\hline Tanker & 174 & 0.80 & 14.5 & 0.181 & 65 & 25 & 10 & 28.42 & 21.03 \\
\hline B. carrier & 290 & 0.83 & 15 & 0.145 & 66 & 24 & 10 & 29.76 & 22.54 \\
\hline B. carrier & 180 & 0.80 & 14 & 0.171 & 65 & 25 & 10 & 28.41 & 21.19 \\
\hline Container & 334 & 0.64 & 26 & 0.234 & 63 & 12 & 25 & 34.99 & 20.67 \\
\hline Container & 232 & 0.65 & 23.5 & 0.250 & 60 & 10 & 30 & 32.48 & 18.05 \\
\hline Cat. ferry & 80 & 0.47 & 36 & 0.700 & 30 & 10 & 60 & 29.80 & 7.89 \\
\hline
\end{tabular}

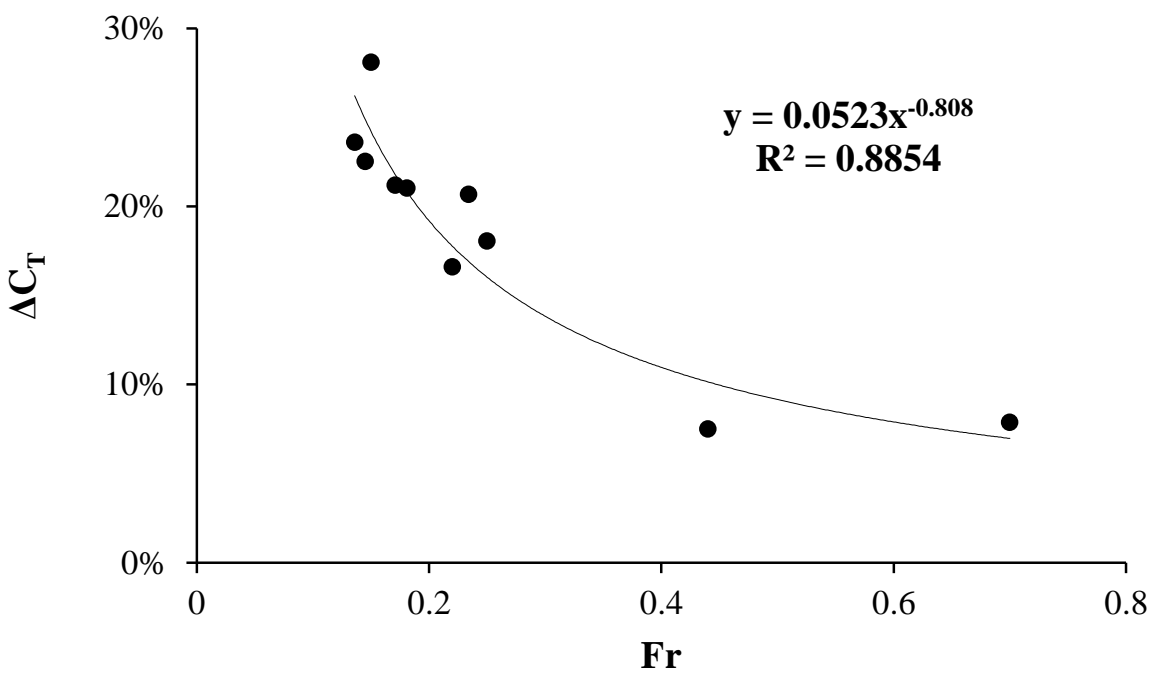

Fig. 7. Relationship of $\mathrm{Fr}$ and $\% \Delta C_{T}$ due to the roughness

\section{Conclusions}

The resolved RANS CFD simulations were conducted to determine the drag penalty of ships from a recently cleaned and painted ship hull roughness ("orange peel" roughness). The results showed that the "orange peel" roughness hull could produce a significant drag penalty for large ships, with an estimated increase of $33 \%-35 \%$ in $C_{F}$ compared to the smooth surface. The roughness could increase the total resistance $\left(C_{T}\right)$ by $7.5 \%-28 \%$. Based on the comparison of the drag penalty results with the type of ship, the type of ship which is most affected by the roughness is a ship that has a higher frictional resistance ratio compared to other resistance components $\left(C_{F} / C_{R}\right)$ or it has lower Froude ( $\mathrm{Fr}$ ) number. Thus, the lower $\mathrm{Fr}$ then, the higher the drag penalty due to the roughness. According to the result, it can be an early warning to pay more attention to the quality of the surface hull smoothness of the ship, especially for large vessels, in order to prevent increased levels of emissions in the air.

\section{Acknowledgment}

The first author wished to thank the Ministry of Research, Technology and Higher Education Republic of Indonesia for funding his study under PMDSU Batch 3 scheme at ITS. Part of the work is funded by Institut Teknologi Sepuluh Nopember through Abdimas 2018 Grants (Contract Number: 1198/PKS/ITS/2018), the Newton Fund Foundation and the British Council and the Australia Research Council. 


\section{References}

[1] Smith, T. W. P., J. P. Jalkanen, B. A. Anderson, J. J. Corbett, J. Faber, S. Hanayama, E. O'Keeffe et al. "A.(2014). Third IMO Greenhouse Gas Study 2014." International Maritime Organization (IMO) 327.

[2] Wang, Haifeng, and Nicholas Lutsey. "Long-Term Potential to Reduce Emissions from International Shipping by Adoption of Best Energy-Efficiency Practices." Transportation Research Record 2426, no. 1 (2014): 1-10.

https://doi.org/10.3141/2426-01

[3] Buhaug, $\varnothing$., J. J. Corbett, V. Eyring, $\varnothing$. Endresen, J. Faber, S. Hanayama, D. S. Lee et al. "Second IMO GHG Study, 2009. International Maritime Organization (IMO)." Buhaug $\varnothing$, Corbett JJ, Endresen $\varnothing$, Eyring V, Faber J, Hanayama S, Lee DS, Lee D, Lindstad and K, Markowska AZ, Mjelde A, Nelissen D, Nilsen J, Pålsson C, Winebrake JJ, Wu W, Yoshida. London, UK. Retrieved November 4 (2009): 2012.

[4] Carlton, J., J. Aldwinkle, and J. Anderson. "Future ship powering options: exploring alternative methods of ship propulsion." London: Royal Academy of Engineering (2013).

[5] Marine Environment Protection Committee. "guidelines on the method of calculation of the attained energy efficiency design index (EEDI) for new ships." Resolution MEPC 212 (2012): 63.

[6] MEPC, RESOLUTION. "2016 GUIDELINES FOR THE DEVELOPMENT OF A SHIP ENERGY EFFICIENCY MANAGEMENT PLAN (SEEMP)." International Maritime Organization. London 2 (2012).

[7] Molland, A. F., S. R. Turnock, D. A. Hudson, and I. K. A. P. Utama. "Reducing ship emissions: a review of potential practical improvements in the propulsive efficiency of future ships." Transactions of The Royal Institution of Naval Architects Part A: International Journal of Maritime Engineering 156 (2014): 175-188.

[8] Hakim, M. L., B. Nugroho, M. N. Nurrohman, I. K. Suastika, and I. K. A. P. Utama. "Investigation of fuel consumption on an operating ship due to biofouling growth and quality of anti-fouling coating." In IOP Conference Series: Earth and Environmental Science, vol. 339, no. 1, p. 012037. IOP Publishing, 2019. https://doi.org/10.1088/1755-1315/339/1/012037

[9] Schultz, M. P., J. A. Bendick, E. R. Holm, and W. M. Hertel. "Economic impact of biofouling on a naval surface ship." Biofouling 27, no. 1 (2011): 87-98.

https://doi.org/10.1080/08927014.2010.542809

[10] MEPC, Resolution, and International Maritime Organization-Marine Environment Protection Committee. "2011 Guidelines for the Control and Management of Ships'biofouling to Minimize the transfer of Invasive Aquatic Species." MEPC 62 (2011): 24.

[11] Schultz, Michael P. "Effects of coating roughness and biofouling on ship resistance and powering." Biofouling 23, no. 5 (2007): 331-341.

https://doi.org/10.1080/08927010701461974

[12] Demirel, Yigit Kemal, Osman Turan, and Atilla Incecik. "Predicting the effect of biofouling on ship resistance using CFD." Applied Ocean Research 62 (2017): 100-118.

https://doi.org/10.1016/i.apor.2016.12.003

[13] Demirel, Yigit Kemal, Dogancan Uzun, Yansheng Zhang, Ho-Chun Fang, Alexander H. Day, and Osman Turan. "Effect of barnacle fouling on ship resistance and powering." Biofouling 33, no. 10 (2017): 819-834. https://doi.org/10.1080/08927014.2017.1373279

[14] Uzun, Dogancan, Refik Ozyurt, Yigit Kemal Demirel, and Osman Turan. "Does the barnacle settlement pattern affect ship resistance and powering?." Applied Ocean Research 95 (2020): 102020.

https://doi.org/10.1016/i.apor.2019.102020

[15] Sarakinos, Sotirios, and Angela Busse. "An algorithm for the generation of biofouled surfaces for applications in marine hydrodynamics." In Recent Advances in CFD for Wind and Tidal Offshore Turbines, pp. 61-71. Springer, Cham, 2019.

https://doi.org/10.1007/978-3-030-11887-7 6

[16] Monty, J. P., E. Dogan, R. Hanson, A. J. Scardino, B. Ganapathisubramani, and N. Hutchins. "An assessment of the ship drag penalty arising from light calcareous tubeworm fouling." Biofouling 32, no. 4 (2016): 451-464.

https://doi.org/10.1080/08927014.2016.1148140

[17] Kodama, Yoshiaki, Akira Kakugawa, Takahito Takahashi, and Hideki Kawashima. "Experimental study on microbubbles and their applicability to ships for skin friction reduction." International Journal of Heat and Fluid Flow 21, no. 5 (2000): 582-588.

https://doi.org/10.1016/S0142-727X(00)00048-5

[18] Schultz, Michael P. "Frictional resistance of antifouling coating systems." J. Fluids Eng. 126, no. 6 (2004): 1039-1047. https://doi.org/10.1115/1.1845552

[19] Demirel, Yigit Kemal, Mahdi Khorasanchi, Osman Turan, Atilla Incecik, and Michael P. Schultz. "A CFD model for the frictional resistance prediction of antifouling coatings." Ocean Engineering 89 (2014): 21-31. 
https://doi.org/10.1016/j.oceaneng.2014.07.017

[20] Atencio, Bercelay Niebles, and Valery Chernoray. "A resolved RANS CFD approach for drag characterization of antifouling paints." Ocean Engineering 171 (2019): 519-532.

https://doi.org/10.1016/i.oceaneng.2018.11.022

[21] Utama, I. K. A. P., Bagus Nugroho, Cheng Chin, Muhammad Luqman Hakim, Fredhi Agung Prasetyo, Mohammad Yusuf, I. Ketut Suastika, Jason Monty, Nicholas Hutchins, and Bharathram Ganapathisubramani. "A study of skin friction drag from realistic roughness of a freshly cleaned and painted ship hull." In International Symposium on Marine Engineering (ISME). 2017.

[22] Ali, Arifah, Adi Maimun, and Yasser Mohamed Ahmed. "Analysis of Resistance and Generated Wave around Semi SWATH Hull at Deep and Shallow Water." Journal of Advanced Research in Fluid Mechanics and Thermal Sciences 58, no. 2 (2019): 247-260.

[23] Sikirica, Ante, Zoran Čarija, Lado Kranjčević, and Ivana Lučin. "Grid Type and Turbulence Model Influence on Propeller Characteristics Prediction." Journal of Marine Science and Engineering 7, no. 10 (2019): 374. https://doi.org/10.3390/jmse7100374

[24] Yanuar and Sulistyawati, W. "CFD investigation of pentamaran ship model with chine hull form on the resistance characteristics." In IOP Conference Series: Materials Science and Engineering, vol. 316, no. 1, p. 012059. IOP Publishing, 2018. https://doi.org/10.1088/1757-899X/316/1/012059

[25] Ashrafian, Alireza, Helge I. Andersson, and Michael Manhart. "DNS of turbulent flow in a rod-roughened channel." International Journal of Heat and Fluid Flow 25, no. 3 (2004): 373-383. https://doi.org/10.1016/i.ijheatfluidflow.2004.02.004

[26] Lee, Jae Hwa, Hyung Jin Sung, and Per-Åge Krogstad. "Direct numerical simulation of the turbulent boundary layer over a cube-roughened wall." Journal of Fluid Mechanics 669 (2011): 397-431. https://doi.org/10.1017/S0022112010005082

[27] Orlandi, Paolo, and Stefano Leonardi. "DNS of turbulent channel flows with two-and three-dimensional roughness." Journal of Turbulence 7 (2006): N73. https://doi.org/10.1080/14685240600827526

[28] Cui, Jie, Virendra C. Patel, and Ching-Long Lin. "Large-eddy simulation of turbulent flow in a channel with rib roughness." International Journal of Heat and Fluid Flow 24, no. 3 (2003): 372-388. https://doi.org/10.1016/S0142-727X(03)00002-X

[29] Saito, Namiko, and D. I. Pullin. "Large eddy simulation of smooth-rough-smooth transitions in turbulent channel flows." International Journal of Heat and Mass Transfer 78 (2014): 707-720. https://doi.org/10.1016/i.ijheatmasstransfer.2014.06.088

[30] Pan, Ying, Marcelo Chamecki, and Scott A. Isard. "Large-eddy simulation of turbulence and particle dispersion inside the canopy roughness sublayer." Journal of fluid mechanics 753 (2014): 499-534. https://doi.org/10.1017/ifm.2014.379

[31] Xie, Zhengtong, and lan P. Castro. "LES and RANS for turbulent flow over arrays of wall-mounted obstacles." Flow, Turbulence and Combustion 76, no. 3 (2006): 291. https://doi.org/10.1007/s10494-006-9018-6

[32] O'Sullivan, J. P., R. Pecnik, and G. laccarino. "Investigating turbulence in wind flow over complex terrain." In Proceedings of the Summer Program, pp. 129-139. 2010.

[33] Ferziger, Joel H., Milovan Perić, and Robert L. Street. Computational methods for fluid dynamics. Vol. 3. Berlin: springer, 2002. https://doi.org/10.1007/978-3-642-56026-2

[34] Menter, Florian R. "Two-equation eddy-viscosity turbulence models for engineering applications." AIAA journal 32, no. 8 (1994): 1598-1605. https://doi.org/10.2514/3.12149

[35] Anderson John, D. "Computational fluid dynamics: the basics with applications." Science/Engineering/Math. McGraw-Hill Science (1995).

[36] Schoenherr, Karl Ernest. "Resistance of flat surfaces moving through a fluid." Trans. Soc. Nav. Archit. Mar. Eng. 40 (1932): 279-313.

[37] Molland, Anthony F., Stephen R. Turnock, and Dominic A. Hudson. Ship resistance and propulsion. Cambridge university press, 2017. https://doi.org/10.1017/9781316494196

[38] ITTC. "1978 ITTC Performance Prediction Method." International Towing Tank Confterence - Recommended Procedures and Guidelines (2017). 